\title{
Primera evidencia de Aedes albopictus en el departamento del Putumayo, Colombia
}

\section{First evidence of Aedes albopictus in Putumayo department, Colombia Primeira evidência de Aedes albopictus em Putumayo, Colômbia}

Keila Ortiz-Canamejoy, MD., Esp.*

Ana Carolina Villota, MD., Esp., Biol., Esp.**

\section{Sra. Editora:}

El Aedes (Stegomyia) albopictus (Skuse, 1894) se denomina también "mosquito tigre" asiático (1) y, al igual que el Ae. aegypti (Linnaeus, 1762), se lo ha identificado en algunos países del continente asiático como importante vector de dengue (2), la más importante enfermedad viral de transmisión vectorial que presenta un fuerte impacto social debido a que se distribuye fundamentalmente en zonas urbanas; es altamente incapacitante y en algunos casos conduce a la muerte (3). Se ha reportado que el Ae. albopictus puede transmitir, experimental o naturalmente 22 tipos diferentes de arbovirus (4); entre estos, los cuatro serotipos de dengue y de los virus de la encefalitis equina del este (5) y la japonesa (6), así como también del virus chikungunya (7) y el del oeste del Nilo $(8,9)$. Además, se ha documentado que puede transmitir el virus de la fiebre amarilla, por lo cual se lo considera como vector puente entre los ciclos de transmisión selvática y urbana (5). Adicionalmente, en zonas endémicas para el dengue, en las cuales se presenten casos de fiebre amarilla, existe el riesgo potencial de que se urbanice esta enfermedad. Por este motivo resulta de interés compartir con los lectores de la revista MedUNAB la experiencia de la primera evidencia de Aedes albopictus en el departamento del Putumayo y mostrar cómo a través de la vigilancia entomológica liderada por el Laboratorio de Salud Pública y con el apoyo de auxiliares del Programa de Enfermedades Transmitidas por vectores (ETV), de la Secretaria de Salud del departamento del Putumayo y del Instituto Nacional de Salud (INS) se determinó la especie.

Aedes albopictus, por la tolerancia de sus huevos al frío, ha ido invadiendo diferentes regiones como Siberia y Norte de China, las islas Salomon, Papua (Nueva Guinea), Australia (donde fue rápidamente

* Médico, Profesional de Apoyo del área de Entomología y Epidemiología del Laboratorio de Salud Pública de Putumayo, Colombia.

** Médico, Especialista en epidemiología, Bióloga, Coordinadora del Laboratorio de Salud Pública de Putumayo, Colombia

Correspondencia: Keila Ortiz Canamejoy, Profesional de Apoyo del área de Entomología y Epidemiología del Laboratorio de Salud Pública de Putumayo, Colombia. E-mail: keilaortiz70@gmail.com 
erradicado), Nueva Zelandia y las Islas del Pacífico (10). También se informó su presencia en Europa y África (11). En agosto de 1985 fue encontrado por primera vez en América, al ser capturado en los alrededores de Houston, Texas (12). Su distribución se ha extendido rápidamente a otros estados de los Estados Unidos y a otros países latinoamericanos. En Suramérica el primer registro de Ae. Albopictus fue registrado en Brasil en 1986 (13) posteriormente en República Dominicana, Mexico, Guatemala, el Salvador y Bolivia (3, 14 y 15).

El 20 de marzo de 1998 se capturaron ejemplares adultos en Leticia - Amazonas, siendo este el primer informe de la presencia de $A$ albopictus en Colombia (16). Posteriormente fue reportado en el 2001 en Buenaventura (17); en 2007 en Cali (18); en 2010 en Barrancabermeja (19); en Cauca y Santander (Betsy Bello N, comunicación personal) (20); en 2011 en Medellín (20) y en el 2016 en Chocó (21). Hasta la fecha el Laboratorio de Entomología del INS ha registrado la presencia en 52 localidades de 11 departamentos del país.

A continuación se especifican algunas características topográficas y climáticas del territorio Colombiano entre ellas la Cuenca Amazónica se ha dividido en tres grandes subregiones: llanura amazónica, piedemonte amazónico y la andinoamazonía; en general, con alturas que sobrepasan los 3.500M.S.N.M.y que por suconformación topográfica presenta los pisos térmicos cálido, medio, frío y páramo. Además de esto, al oriente presenta una zona plana o ligeramente ondulada, cubierta de selva y con alturas inferiores a los 300 M.S.N.M., que solo ofrece el piso térmico cálido y altas precipitaciones (22). El clima del Departamento de Putumayo es muy variado, debido principalmente a factores como la latitud, altitud, orientación de los relieves montañosos, los vientos, etc.; todo el departamento tiene una humedad relativa del aire superior al $80 \%$. La variedad de su topografía se conjuga con la variedad climática; a excepción de los nevados, posee todos los pisos térmicos. La llanura amazónica de clima cálido y húmedo, contrasta con el clima frío de sus altas montañas y Valle de Sibundoy (22).

En el departamento del Putumayo se presentan las condiciones ambientales, geográficas y climáticas adecuadas para la sobrevivencia de los insectos vectores de enfermedades en 9 de sus 13 municipios; estos son Mocoa, Villagarzón, Puerto Caicedo, Puerto Asís, Orito, San Miguel, Valle del Guamuez, Puerto Guzmán y Leguízamo (23). Mocoa es considerado uno de los municipios más importantes del departamento del Putumayo debido a que es la capital del departamento. De acuerdo al Plan Básico de Ordenamiento Territorial, "el Municipio de Mocoa está ubicado sobre el Piedemonte amazónico, al noroeste del Departamento del Putumayo (Mapa 1), en las coordenadas: $1{ }^{\circ} 08^{\prime}$ Latitud Norte, y $76^{\circ} 38^{\prime}$ Longitud Oeste" (24). Limita al norte con los departamentos del Cauca (municipio de Santa Rosa) y Nariño (municipio del Tablón); por el oriente con el departamento del Cauca y el municipio de Puerto Guzmán; por el sur con el municipio de Puerto Caicedo; por el occidente desde la desembocadura del río Blanco al río Putumayo (24).

"Cuenta con una extensión de 1.263 kilómetros cuadrados y una población de 31.719 habitantes. Presenta alturas que oscilan entre los 350 y 3.200 M.S.N.M," (25) posee una precipitación que se aproxima a los $5.062 \mathrm{~mm}$ anuales y temperaturas que oscilan entre los 24 y $26^{\circ} \mathrm{C}(25)$.

El 31 de marzo de 2017 se presentó un evento natural, denominado avenida torrencial. Este hecho alertó a las instituciones de orden municipal, departamental y nacional. El Laboratorio de Entomología por Salud Pública (LDSP), con el apoyo de auxiliares del programa de ETV de la Secretaría de Salud del departamento de Putumayo, desarrollaron búsquedas activas del vector Aedes aegypti en los diferentes barrios del municipio, con el objetivo de identificar la existencia de vectores, sus criaderos y evitar su propagación. Las muestras recolectadas fueron enviadas al Laboratorio de Entomología INS para su respectivo análisis, encontrando como resultado la presencia del vector Aedes albopictus en las muestras tomadas en los asentamientos rurales de 15 de Mayo y Nueva Esperanza. Con los hallazgos, el INS recomienda realizar un muestreo más amplio en diferentes zonas del Municipio.

Durante los días 10 al 17 de octubre de 2017, en el segundo muestreo, la identificación taxonómica se realizó por el laboratorio de entomología del LDSP y la confirmación de dichos ejemplares se hizo por parte del Laboratorio de Entomología del INS. Como resultado se confirmó la presencia del vector Aedes albopictus en los asentamientos rurales de 15 de Mayo, Nueva Esperanza y en el Porvenir. Las larvas fueron preservadas en alcohol al 70\% y algunas larvas se dejaron en agua para que emergieran a adulto con el fin de obtener muestras para la colección entomológica del departamento. 
Los resultados encontrados en los asentamientos fueron los siguientes:

El 15 de Mayo se identificaron 6 larvas y 2 adultos de Aedes albopictus; por otra parte, se identificaron 13 larvas y 11 adultos de Aedes aegypti. Las muestras se encuentran con el código 168 y 169 en el laboratorio de entomología del LDSP.

En Nueva Esperanza se identificaron 39 larvas y 7 adultos de Aedes albopictus; de Aedes aegypti se identificaron 16 larvas y 19 adultos. Estas muestras se encuentran en el laboratorio con los códigos 171, 174, 175, 177, 178, 179, 181, 183, 184, 185.

En El Porvenir se identificaron 11 larvas y 1 adulto de Aedes albopictus y de Aedes aegypti 6 larvas y 8 adultos. Estas muestras se encuentran en el laboratorio con los códigos 183, 184 y 185.

Todos los depósitos encontrados en la segunda búsqueda fueron hallados en el peridomicilio de las viviendas: en el asentamiento de 15 de Mayo se encontró Ae. albopictus en un diverso o inservible, en Nueva Esperanza fue encontrado en un diverso y en llantas y en el barrio Porvenir en una llanta.

La dispersión de Ae. albopictus en diferentes países se ha debido a la introducción de larvas y huevos mediante el intercambio comercial de mercancía como neumáticos (12), tocones de bambú y demás elementos que son

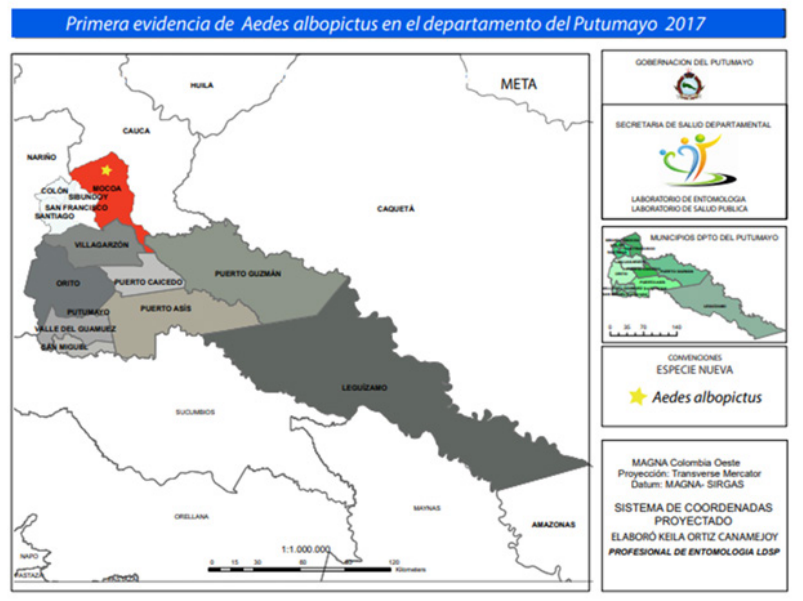

Figura 1. Mapa ubicación de Aedes albopictus en el departamento del Putumayo

Fuente: Elaboración propia de Keila Ortiz C - Profesional de Apoyo Área de Entomología y Epidemiología, Laboratorio de Salud Pública de Putumayo, 2018 empleados por este vector, en su lugar de origen, como sitios para su ovipostura $(26,27)$. En el departamento del Putumayo se desconocen los medios que generaron la colonización de Aedes albopictus; sin embargo, es comprensible la presencia en Mocoa dada su ubicación estratégica como punto importante de entradas y de salidas por vía terrestre y fluvial, con gran movilidad humana e intercambio económico y comercial, a diferencia de los otros municipios del departamento. Mocoa se comunica con los departamentos del Cauca por el río Caquetá y con el departamento de Nariño por vía terrestre, departamentos infectados por el mismo vector, según el INS. Cabe resaltar que después de la catástrofe ocurrida en el municipio entraron ayudas humanitarias por vía terrestre y aérea, internacionales y nacionales que podrían ser un canal de entrada de este vector.

Las larvas se encuentran tanto en criaderos naturales como artificiales. Los principales criaderos naturales son los huecos de los árboles, los huecos de bambú, los huecos de rocas, las cáscaras de coco y las axilas de las plantas, incluidas las bromelias (28). En este estudio los depósitos donde se encontró el vector son diversos o inservibles y llantas, los cuales son almacenados o desechados en el peridomicilio de las viviendas, lo que demuestra deficiencias en los servicios básicos de recolección de residuos sólidos, además del desconocimiento sobre la ecología de los mosquitos vectores de enfermedades que favorecen la cría y dispersión de esta especie.

En este estudio se pudo observar la presencia de Aedes albopictus con Aedes aegypti en los tres asentamientos rurales de 15 de Mayo, Nueva Esperanza y Porvenir. En muchas regiones, la distribución de A. albopictus se superpone con la de $A$. aegypti; sin embargo, $A$. albopictus prefiere áreas suburbanas y rurales con abundante vegetación alrededor de casas y edificios. Por su parte, A. aegypti predomina en los sectores más urbanizados de las ciudades (29). Esta tendencia se fundamenta en que Ae. albopictus fue originalmente una especie selvática que se procreaba y alimentaba en los márgenes de los bosques y que comenzó a adaptarse al medio urbano (27). Por otro lado, se ha observado que $A$. albopictus invade los criaderos y desplaza $A$. aegypti por competencia. Allí, las larvas de $A$. albopictus se encuentran en mayor ventaja para sobrevivir, siendo rápidamente dominantes $(30$ y 31$)$.

Aunque Aedes albopictus no se ha incriminado como vector en ningún brote ocurrido en América (32), existen diferentes estudios que demuestran la importancia epidemiológica de este vector; en el 
continente asiático es el transmisor del virus dengue, principalmente en áreas rurales (22), el cual puede ser transmitido por vía transovárica y sexual $(32,33)$

En Buenaventura, Colombia se ha comprobado la infección natural con DENV-1 y DENV-2 (44) y con DENV-2 y DENV-3 en México (34). En Minas Gerais, Brasil, también se encontraron larvas infectadas por DENV- 1 (35). Además al dengue se lo ha incriminado como vector potencial del virus chikungunya (7), del virus de la encefalitis japonesa (6) y de fiebre amarilla, lo cual constituye, un riesgo al ser el posible enlace entre los ciclos de transmisión de la fiebre amarilla selvática y urbana (5).

Hay que resaltar que, aunque se ha demostrado que es menos competente para la transmisión de los virus del dengue en algunas regiones, A. albopictus podría adaptarse en el futuro y aumentar su competencia vectorial (36). Por esta razón la Secretaria de Salud del departamento del Putumayo, aunque ya realizó acciones de control y de promoción, debe continuar con la realización de diferentes acciones de control. A pesar de que se toman estas determinaciones, se hace más difícil el control con relación al de Ae. aegypti porque Ae. albopictus se encuentra en el peridomicilio y tiene un amplio rango de hábitats, incluyendo los bosques.

En casos de brotes de dengue o de otras enfermedades en que pueda estar implicado este vector, se debe hacer control con insecticidas químicos, tanto de productos dedicados al exterminio de mosquitos adultos (ULV e intervención casas a casa), como de larvas (larvicidas y control biológico de prolongada eficacia residual). No obstante, se ha demostrado que el mosquito tiene la capacidad de desarrollar resistencia muy rápidamente, (4) por lo que estos procesos deben ser monitoreados. De la misma manera se debe enfatizar en promover acciones de Educación, Información y Comunicación (EIC) intersectoriales en la comunidad en torno a la recolección y eliminación de criaderos que acumulen agua, con especial énfasis en llantas viejas, además de enseñarle a la población a cambiar el agua de floreros, tanques y jarros y de la óptima limpieza de las paredes de los mismos para desprender los huevos de Aedes. La campaña de educación primaria en salud debe ser permanente con el empleo de todos los medios al alcance para realizarla, con el fin de reducir las densidades a un nivel en que la transmisión de las enfermedades sea poco probable.

Además de estas estrategias de control, se debe continuar con un plan de vigilancia en otras zonas de la ciudad que presenten las condiciones ecoepidemiológicas para la presencia del nuevo vector y la transmisión de la enfermedad, determinar los sitios de cría, naturales y artificiales, preferidos por $\mathrm{Ae}$. albopictus y la productividad de estos; estimar bajo condiciones de coexistencia el posible potencial de desplazamiento de Ae. albopictus sobre Ae. Aegypti.

En este reporte se registró la presencia de A. albopictus en el Putumayo, ampliándose así su distribución en el país, lo cual resalta su importancia en Salud Pública por ser vector de los virus del dengue, del chikungunya y de otras arbovirosis.

\section{Agradecimientos}

A los auxiliares del Programa de Enfermedades Transmitidas por Vectores por el apoyo en el trabajo de campo, a la Dra. Luz Dary Ortega Secretaria de Salud Departamental año 2017, a la Dra. Glinys Edith Diaz Llerena Secretaria de Salud Departamental año 2018 por sus gestiones y apoyo en la realización de las acciones de vigilancia Entomológica en el departamento del Putumayo y al Grupo de Entomología de la Subdirección Red Nacional de Laboratorios del Instituto Nacional de Salud, especialmente a la Dra. Sussane Carolina Ardila por el Apoyo en el direccionamiento de esta investigación y a John Jairo González por el apoyo en el trabajo de campo.

\section{Referencias}

1. Huang YM. Neotype designation for Aedes (Stegomyia) albopictus (Skuse) (Diptera:Culicidae). Proc Ent Soc Wash. 1968;70:297-302.

2. Reiter P, Fontenille D, Paupy C. Aedes albopictus as an epidemic vector of chikungunya virus: another emerging problem?. Lancet Infect Dis. 2006;6:463464.

3. World Health Organization (WHO). Dengue and dengue haemorrhagic fever. Geneva, March 2009. Fact sheet No 117.

4. Estrada-Franco J. Biology, disease relationship, and control of Aedes albopictus. Technical Paper PAHO. 1995; 42:51.

5. Gratz NG. Critical review of the vector status of Aedes albopictus. Med Vet Entomol. 2004;18:215227.

6. Rosen L, Tesh R, Lien JC, Cross JH. Transovarial transmission of Japanese encephalitis virus by 
mosquitoes. Science. 1978;199:909-911.

7. Mangiafico JA. Chikungunya virus infection and transmission in five species of mosquito. Am J Trop Med Hyg. 1971;20:642-645.

8. Holick J. Discovery of Aedes albopictus infected with West Nile virus in Southeastern Pennsylvannia. J Am Mosq. Control Assoc. 2002;18:131.

9. Turell MJ, O'Guinn ML, Dohm DJ, Jones JW. Vector competence of North

10. World Organization. Dengue in the Peoples REpublic of China, South-East Asian an Western Pacific Regions. Dengue Newaletterr 1980; 6(1.2):14. En: Presencia de Aedes albopictus en Leticia, Amazonas, Colombia. Ivan Dario Velez, et al. 1998. Biomedica [Internet]. 1998 [citado 14 de octubre de 2017]; 18(3): 192-198. Recuperado a partir de: https://www.revistabiomedica.org/index. php/biomedica/article/download/990/110

11. Scanion J, Esah S. Distribution in altitude of mosquitoes in northern Thailand. Mosq News 1965; 26 (2), 141-2. Citado En: Presencia de Aedes albopictus en Leticia, Amazonas, Colombia. Ivan Dario Velez, et al. 1998. Biomedica [Internet]. 1998 [citado 14 de octubre de 2017];18(3):192198. Recuperado a partir de: https://www. revistabiomedica.org/index.php/biomedica/article/ download/990/110

12. Centers for Disease Control and Preention (CDC). Aedes albopictus Introduction in Texas. MMWR 1986; 35:141-2.

13. Forattini OP. Identificao de Aedes (Stegomyia) albopictus no Brasil. Rev Saúde Pública. 1986;20:244 - 5

14. OPS. Estudio sobre la factibilidad de la erradicación del Aedes aegypti. CE 118/96.1996. Citado En: Presencia de Aedes albopictus en Leticia, Amazonas, Colombia. Ivan Dario Velez, et al. 1998. Biomedica [Internet]. 1998[citado 14 de octubre de 2017];18(3):192-198. Recuperado a partir de: https://www.revistabiomedica.org/index.php/ biomedica/article/download/990/110

15. PAHO. The feasibility of erradicating Aedes aegypti in the Americas. Pan Am J Health 1997; (1):6872. Citado En: Presencia de Aedes albopictus en Leticia, Amazonas, Colombia. Ivan Dario Velez, et al. 1998. Biomedica [Internet]. 1998[citado 14 de octubre de 2017]; 18(3):192-198. Recuperado a partir de: https://www.revistabiomedica.org/index. php/biomedica/article/download/990/110

16. Velez Ivan Dario Etal. Presencia de Aedes albopictus en Leticia, Amazonas, Colombia. Biomedica [Internet]. 1998 [citado 14 de octubre de 2017]; 18 (3): 192 -198. Recuperado a partir de: https://www. revistabiomedica.org/index.php/biomedica/article/ download/990/110

17. Surez M. Aedes albopictus (Scuse) (Diptera: Culicidae) en Buenaventura, Colombia. Inf Quinc demiológico Nac. 2001;6:221-4.

18. Céllar- Jiménez ME, Velásquez-Escobar OL, González-Obando R. Detección de Aedes albopictus (Skuse) (Diptera: Culicidae) en la ciudad de Cali, Valle del Cauca, Colombia. Biomedica. 2007;27:273-9. doi.org/10.7705/biomedica. v27i2.224

19. Gutierres M, Et al. Hallazgos de Aedes albopictus (Diptera: Culicidae) en el municipio de Barrancabermeja, Colombia. Biomedica. 2011;31:26. Memorias, XX Congreso Latinoamericano de Parasitología, Bogotá, D.C, mayo de 2011.

20. Guillermo Rua-Uribe, Carolina Suárez Acosta, Viviana Londoño, James Sanchez4, Raúl Rojo O, Betsy Bello Novoa. Primera evidencia de Aedes albopictus (Skuse) (Diptera: Culicidae) en la ciudad de Medellín, Antioquia - Colombia. Este artículo es producto del proyecto de investigación evaluación de la presencia de Aedes albopictus en Medellín año 2011, convenio de asociación 4600029233 de 2010 entre la Secretaria de Salud de Medellín y la Universidad de Antioquia. Revista de Salud Pública de Medellín [Internet]. 2011[citado 11 de octubre de 2017]; Volumen 5. Recuperado a partir de: https://www.medellin.gov.co/irj/go/km/docs/ wpccontent/Sites/Subportal\%20del\%20Ciudadano/ Salud/Secciones/Plantillas\%20Gen\%C3\%A9ricas/ Documentos/2012/Revista\%20Salud/Revista\%20 Vo1.\%20 5\%20N\%C 2\%B 0\%201/7.\%20 Primera\%20evidencia\%20de.pdf.

21. Carvajal, Jose, Et al. Detección de Aedes albopictus (Skuse) (Diptera: Culicidae) en el municipio de Istmina, Chocó, Colombia. Biomédica [Internet]. 2016;36(3):438-446. doi.org/10.7705/biomedica. v36i3.2805.

22. Plan departamental de Desarrollo. Putumayo solidario y competitivo 2012- 2015:6-10.

23. Estrategia de Gestión Integrada para la promoción, prevención y control de las Enfermedades Transmitidas por Vectores en el Departamento del Putumayo. 2012-2021. 15p.

24. Plan Básico de Ordenamiento Territorial, 
Municipio de Mocoa [citado 10 de noviembre de 2014). Recuperado a partir de: http://cdim.esap. edu.co/BancoMedios/Documentos\%20PDF/ diagnostico $\% 20-\% 20$ mocoa $\% 20 \% 2880 \% 20$ pag\%20-\%201429\%20kb\%29.pdf.

25. CORPOAMAZONIA, 1997 y proyección DANE, 1999 Citados en: Plan Básico de Ordenamiento Territorial, Municipio de Mocoa. http://cdim. esap.edu.co/BancoMedios/Documentos\%20PDF/ diagnostico $\% 20-\% 20$ mocoa $\% 20 \% 2880 \% 20$ pag\%20-\%201429\%20kb\%29.pdf.

26. Hawley WA, Reiter P, Copeland RS, Pumpini CB, et al. Aedes albopictus in North America: Probable introduction in used tires from northern Asia. Science. 1987;236:1114-6.

27. Hawley WA. The biology of Aedes albopictus. J Am Mosq Control Assoc. 1988;4:1-40

28. Ho BC, KL Chan, Chan YC. ill. Control of Aedes vectors. The biology and bionomic of Aedes albopictus (Skuse).ln: Chan YC, et al.,editors. Veclor control in Southeast Asia. Proceedings 1st SEAMEO Workshop. 15-17 August 1972. Singapore; 1972

29. Pant CP, Jatanasen S, Yasuno M. Prevaience of Aedes aegypti ad Aedes albopictus and observations on the ecology of dengue haemorrhagic fever in several areas of Thailand. South Asian J Trop Med Public Health. 1973;4:113-21.
30. O’Meara G, Gettman A, Evans L, Curtis G. The spread of Ae. aihopictus in Florida. Am Entomol. i993;39(3):163-72.

31. Edgerly J, Willey MS, Livdahl TP. The community ecology of Aedes egg hatching: impiications for a mosquito invasion. Ecol Entomol. 1993;18:123-8.

32. Rosen L. Sexual transmission of dengue viruses by Aedes albopictus. Am J Trop Med Hyg. 1987;37:398- 402. 20.

33. Rosen L, Shroyer DA, Tesh RB, Freier JE, Lien JC. Transovarial transmission of dengue viruses by mosquitoes Aedes albopictus and Aedes aegypti. Am J Trop Med Hyg. 1983;32:1108-19.

34. Serufo JC, de Oca HM, Tavares VA, Souza AM, Rosa RV, Jamal MC, et al. Isolation of dengue virus type 1 from larvae of Aedes albopictus in Campos Altos city, State of Minas Gerais, Brazil. Mem do Inst Oswaldo Cruz. 1993;88:503-4. doi. org/10.1590/S0074-02761993000300025

35. Méndez F, Barreto M, Arias JF, Rengifo G, Muñoz J, Burbano ME, et al. Human and mosquito infections by dengue viruses during and after epidemics in a dengueendemic region of Colombia. Am J Trop Med Hyg. 2006;74: 678-83.

36. Gratz NG. Critical review of the vector status of Aedes albopictus. Med Vet Entomol. 2004;18:215227. 